\title{
Anatomy of Frontal Recess and Opening
}

\author{
Hany Amin Riad* \\ Professor, Behna Faculty of Medicine, Egypt
}

*Corresponding author: Hany Amin Riad, Professor, Behna Faculty of Medicine, Egypt.

Received Date: July 25, 2020

Published Date: August 18, 2020

\section{Introduction}

The key to successful surgery in the frontal sinus is a complete understanding of the anatomy of the frontal recess, which is behind the beak of the frontal bone between the lamina papyracea laterally and superior portion of the middle turbinate. It is a hazardous and complex area with a range of anatomical configurations and lot of abnormalities (Figure 1).

\section{Frontal Recess}

The boundaries of the frontal recess are typically formed by the agger nasi cell anteriorly; the lamina papyracea laterally; the most anterior and superior portion of the middle turbinate medially; and the ethmoid bulla, its associated bulla lamella, and the suprabullar cell (if present) posteriorly. This area is called the frontal recess. This is one of the most common regions for residual infection after sinus surgery. Special instruments and training are needed to adequately address obstructions here. Even when special care is taken to examine and protect this area, frontal sinus obstruction can be difficult to correct. The frontal sinus has the longest drainage pathway. Surprisingly, the frontal sinus is not as frequently involved as the maxillary or anterior ethmoid sinuses (Figure 2).

\section{Frontal Ostium}

Together, the frontal sinus and the superior compartment of the frontal sinus drainage pathway resemble an Erlenmeyer flask, with the neck of the flask representing the frontal ostium. The inferior compartment of the frontal sinus drainage pathway could then be conceptualized as directly communicating with a small opening in the base of the flask. The frontal ostium forms the upper border of the superior compartment of the frontal sinus drainage pathway. The superior compartment of the frontal sinus drainage pathway drains posteroinferiorly into a narrow inferior compartment situated always anterior to the ethmoid bulla. The agger nasi air cell is classified as an extramural ethmoid air cell, because it projects anterior to the ethmoid bone. This cell frequently extends to the lacrimal bone and the frontal process of the maxilla. Common anatomic variations affecting the superior compartment of the frontal sinus drainage pathway include osseous septations and marginating air cells.

\section{Dimension of the Frontal Sinus Ostium}

The mean anterior-posterior diameter was $7.22 \pm 2.78 \mathrm{~mm}$ and transverse diameter was $8.92 \pm 2.95$. Mean frontal ostium section was $50.5 \mathrm{~mm} 2$. Most patient can be treated with frontal sinusotomy without the need of drill-out surgery. Uncinate Process anterior attachment variations It may be superiorly attached to the middle tubinate, skull base or lamina paperecae. The inferior compartment of the frontal sinus drainage pathway is formed by the ethmoid infundibulum when the superior portion of the uncinate process attaches to the skull base but is formed instead by the middle meatus when the uncinate process attaches to the lamina papyracea [2] (Figure 3).

In a study visualization of the frontal sinus ostium after resection of the lower portion of the uncinate process was possible in only 11 (18.64\%) nasal cavities. The uncinate process (terminal recess) was the main anatomical structure that impaired the recognition of the frontal sinus ostium, present in 45 (76.27\%) nasal cavities, followed by the ethmoid bulla (16.95\%) and agger nasi cells $(6.78 \%)$. We found that the frontal sinus drained anterior to the uncinate process (anterior terminal recess) in 24 specimens (29.3\%) with an average distance of $3.65 \mathrm{~cm}$ from the pyriform aperture and 58 degrees from the nasal floor. The frontal sinus drained posterior to the uncinate process (posterior terminal recess) in 56 specimens (68.3\%) with an average distance of 4.10 $\mathrm{cm}$ and 65 degrees from the nasal floor. 

In this latter group, most of the sinuses (51 specimens) drained into the ethmoid infundibulum. Two of the specimens had a hypoplastic frontal sinus with no outflow tract at all. The frontal sinus and anterior ethmoid cells drain into a space just inside of the uncinate bone. This space diverts drainage back so that it will be directed down the throat for swallowing. The drainage crosses over the free edge of the uncinate bone and mixes with the drainage coming from the maxillary sinus. The final common path is over the surface of the inferior turbinate [4] (Figure 4).

\section{Common Anatomic Variation}

The most common anatomic variation was agger nasi cells $(80.4 \%)$ followed by pneumatization of the middle concha $(37 \%)$. The least encountered variations were pneumatization of the inferior turbinate, bony dehiscence of the ethmoidal roof, and duplication of the middle and superior turbinates. The frequency of variations did not differ significantly with respect to gender ( $p>0.05)$ except for frontal hypoplasia, which was more often in females $(p<0.05)$. The frontal recess may be pneumatized by various anterior ethmoid cells, which are collectively known as

\section{The medial type}

frontal recess cells. These cells are normal anatomic variations that are present in some combination in most individuals. The clinical relevance of frontal recess cells lies in their potential for causing frontal sinusitis by obstructing frontal sinus outflow at the level of the frontal recess

\section{Anterior relation to frontal recess}

Frontal cells, along with the agger nasi cell, constitute the anterior group of frontal recess cells. Frontal cells are present at CT in $20 \%-33 \%$ of patients, making them extremely common anatomic variants. There are four types of frontal cells described under the system known as the Kuhn classification [5] (Figures 5-8).

\section{Posterior boundary of the frontal recess}

1. Supraorbital ethmoid cells (A),

2. Frontal bullar cells (B),

3. Suprabullar cells (C) make up the posterior group of frontal recess cells. All of the cells in this group are located along the posterior wall of the frontal recess and are bordered posteriorly or superiorly by the anterior skull base (Figure 9).

Figure 4

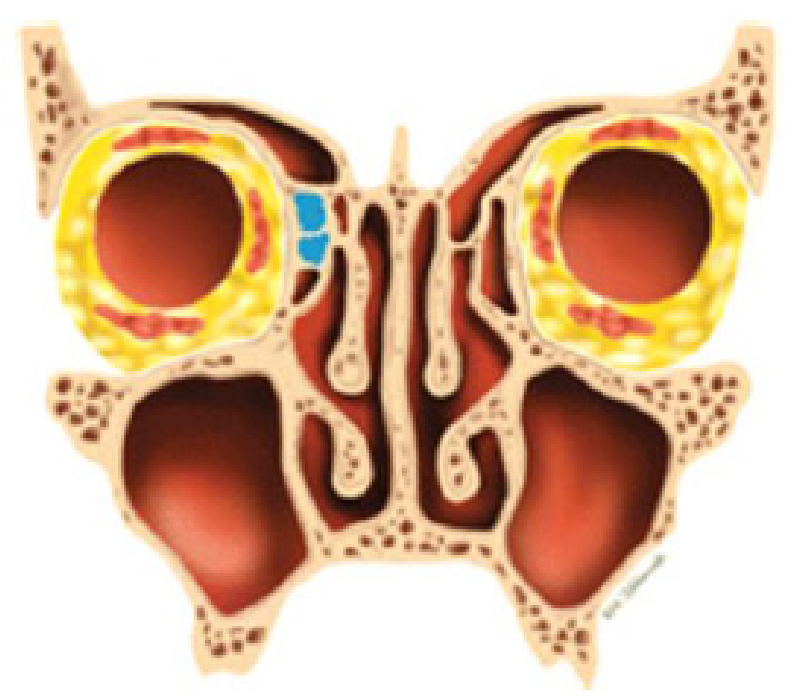

Figure 5 


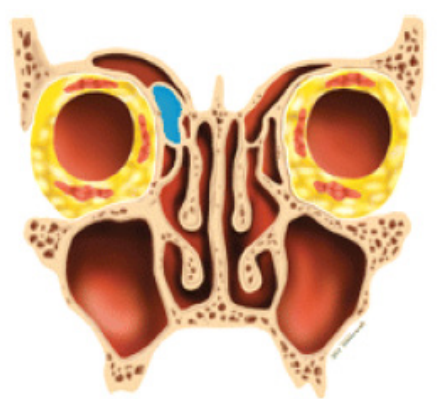

Figure 6: Type II Two or more cells above the agger cell.

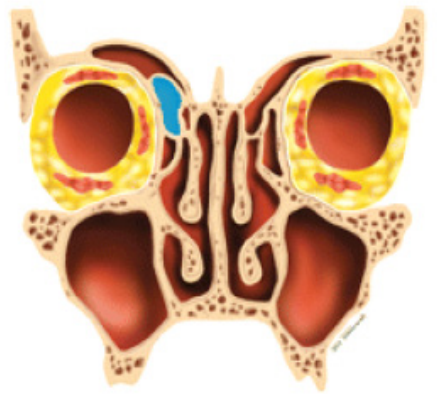

Figure 7: Type III Single cell extending from the agger cell into the frontal sinus.

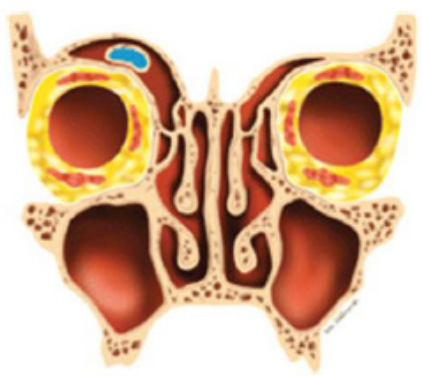

Figure 8: Type Iv Isolated cell within the frontal sinus.
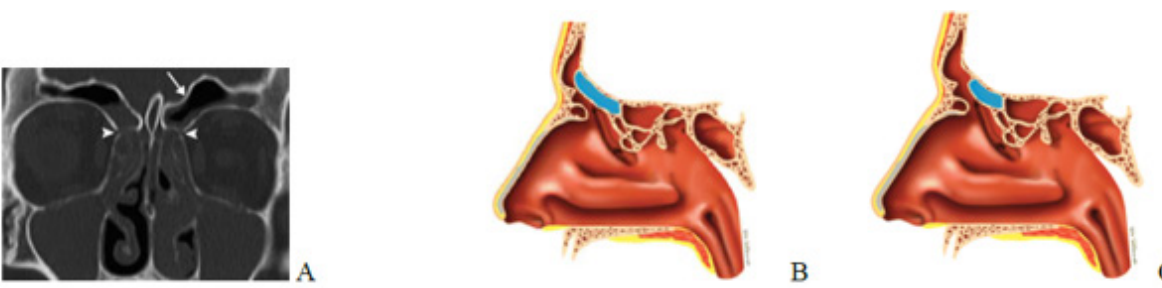

Figure 9

Figure 10

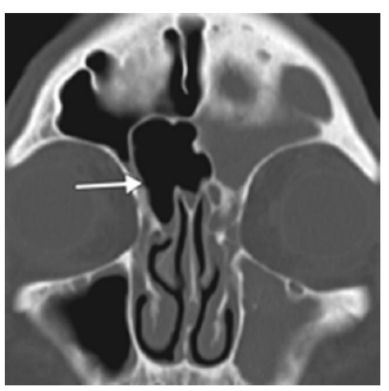


That is made up of the inter-frontal sinus septal cell. This cell represents pneumatization of the inter-frontal sinus septum; when extensive, such pneumatization can extend into the crista galli. These cells drain into the medial frontal recess and can impinge on the frontal sinus ostium (Figure 10).

The introduction of nasal optical devices into clinical practice has revolutionized the diagnostic and surgical approach to all sinonasal pathologies and moreover has imposed the necessity of redefining the anatomy of this region from an endoscopic point of view. Difficulties in learning the techniques of endoscopic sinus surgery are due to the complexity and great anatomic variability of this area together with the tremendous diversity between individuals, and even between the bilateral aspects of each patient. This situation is complicated by the anatomical changes which occur as a result of disease and scarring from previous surgery [6]. In particular, surgery on the frontal recess and frontal sinus remains a challenge for sinus surgeons [7].

\section{Acknowledgement}

None.

\section{Conflict of Interest}

No conflict of interest.

\section{References}

1. Farneti P, Riboldi A, Sciarretta V, Piccin O, Tarchini P, et al. (2017) Usefulness of three-dimensional computed tomographic anatomy in endoscopic frontal recess surgery. Surg Radiol Anat 39(2): 161-168.

2. Michael Friedman, Darius Bliznikas, Ramakrishnan Vydiasagar, Roee Landsberg (2004) Frontal Sinus Surgery 2004: Update of Clinical Anatomy and Surgical Techniques. Operative techniques in otolaryngology-Head and Neck Surgery 15: 23-31.

3. Stammberger H, Posawetz W (1990) Functional endoscopic sinus surgery. Concept, indications and results of the Messerklinger technique. Eur Arch Otorhinolaryngol 247(2): 63-76.

4. Marcus Miranda Lessa, Richards Louis Voegels, Bernardo Cunha Filho, Flavio Sakae, Ossamu Butugan et al. (2007) Frontal recess anatomy study by endoscopic dissection in cadavers. Braz J Otorhinolaryngol 73(2): 204-209.

5. Frederick A Kuhn, William E Bolger, RG Tisdal (1991) The agger nasi cell in frontal recess obstruction: An anatomic, radiologic and clinical correlation. Operative Techniques in Otolaryngology-Head and Neck Surgery 2(4): 226-231.

6. Woodham JD, Doyle PW (1991) Surgical landmarks and resections for the safe performance of conservative endoscopic sinus surgery. J Otolaryngol 20: 451-454.

7. Wormald PJ (2013) Anatomy of the frontal recess and frontal sinus with three-dimensional reconstruction. In: Wormald PJ (Edt.), Endoscopic sinus surgery: anatomy, three-dimensional reconstruction and surgical technique, (3 ${ }^{\text {rd }}$ Edn.) Thieme, New York, USA, p: 45-80. 